\title{
ANALISIS FILOSOFIS TENTANG PENDIDIKAN ISLAM SEBAGAI SUATU SISTEM
}

\author{
Suriadi \\ Institut Agama Islam Sultan Muhammad Syafiuddin Sambas \\ J1. Raya Sejangkung No. 126 Komplek Perguruan Tinggi \\ Sebayan-Sambas Kalimantan Barat \\ E-mail: uriadisambas@gmail.com \\ DOI: $10.29313 /$ tjpi.v6i2.3187
}

Accepted: November 8th, 2017. Approved: January 18th, 2018. Published: January 18th, 2018

\begin{abstract}
This article describes the philosophical analysis of education about Islam as a system, the style of an educational system seems to be influenced by the perspective of each community, group, or nation respectively. This viewpoint is closely related to the philosophical background and their worldview. Because after this life outlook reflects the identity that must be preserved and further developed and passed on to the younger generation of the people concerned. Of the opinion that it can be said, if the Islamic education as a system that has a component, then the style of Islamic education system must have been referring to the source of the teachings of Islam itself, i.e. the Qur'an and Hadith. On that basis, usually formulated a basic foundation of Islamic education, as well as the concept of Islamic education system that is desired. The educational elements include the following: the principle of education, educational, educational material, educational subject, the object of education, methods of education, media education, education evaluation, and environmental education.
\end{abstract}

Keywords: Analisis Filosofis, Pendidikan Islam, Sistem.

\begin{abstract}
ABSTRAK
Artikel ini memaparkan tentang analisis filosofis pendidikan Islam sebagai suatu sistem, corak suatu sistem pendidikan tampaknya dipengarubi oleh cara pandang dari setiap masyarakat, kelompok, atau bangsa masing-masing. Cara pandang ini erat kaitannya dengan latar belakang filsafat dan pandangan bidup mereka. Sebab bagaimanapun pandangan hidup ini mencerminkan jati diriyang harus dipertahankan serta dikembangkan dan selanjutnya diwariskan kepada generasi muda masyarakat bersangkutan. Dari pendapat itu dapat dikatakan, jika pendidikan Islam sebagai suatu sistem yang memiliki komponen, maka corak sistem pendidikean Islam tentulah mengacu kepada sumber ajaran Islam itu sendiri, yaitu Al-Qur'an dan Hadits. Atas dasar itulah, biasanya dirumuskan landasan dasar pendidikan Islam, konsep serta sistem pendidikan Islam yang dikehendaki. Unsur-unsur pendidikan tersebut antara lain adalah sebagai berikut: asas pendidikan, tujuan pendidikan, materi pendidikan, subjek pendidikan, objek pendidikan, metode pendidikan, media pendidikan, evaluasi pendidikan, dan lingkungan pendidikan.
\end{abstract}

Kata kunci: Analysis of Philosophy, Education, Islam, Systems. 


\section{PENDAHULUAN}

Pendidikan tidak berlangsung dalam suatu ruang hampa, melainkan di dalam suatu masya rakat dan kebudayaannya. Praktek pendidikan melibatkan berbagai komponen yang terdapat di dalam masyarakat dan turut berpengaruh terhadap keberhasilan pencapaian tujuan pen-didiikan yang telah ditetapkan.

Pendidikan dipandang sebagai suatu ke-giatan yang bersifat antisipatoris, yaitu kegiatan untuk menyongsong perkembanganperkem-bangan yang diperhitungkan akan terjadi dima-sa depan yang ditentukan oleh persepsi suatu masyarakat pendidikan terhadap kecenderung-an yang ada yang tertarik secara inferensial da-ri fakta-fakta yang ada dalam kehidupan sehari-hari. (Mochtar Buchori, 1994: 44)

Salah satu kecenderungan yang terlihat je-las dari dinamika kehidupan manusia adalah pe-rubahan-perubahan yang dihasilkan oleh usaha umat manusia di bidang ilmu pengetahuan dan teknologi. Perubahanperubahan yang dihasil-kan oleh ketekunan penelitian dipelbagai bidang terasa besar pengaruhnya terhadap aspek kehidupan manusia, maka kehidupan ekonomi, politik, sosial, dan budaya perlu disesuaikan de-ngan kemajuan-kemajuan mutakhir yang ter-capai diberbagai cabang ilmu pengetahuan dan teknologi.

Mempertahankan

dan

mengembangkan eksistensi suatu bangsa atau masyarakat, maka masyarakat sebaiknya berusaha untuk mengenal kecenderungankecenderungan yang terdapat di dalam dan di sekitar dirinya, menyusun gambar-an yang cukup bulat dan lengkap mengenai ma-sa depan yang dihadapinya. Oleh karena itu, sua-tu bangsa atau masyarakat yang ingin mempertahankan dan mengembangkan eksistensinya dituntut untuk membuat sistem pendidikan yang dimilikinya menjadi lebih dinamis dan lebih responsive terhadap perubahanperubahan dan kecenderungan-kecenderungan yang berlangsu-ng. (Mochtar Buchori, 1994: 45)
Sistem pendidikan dalam dirinya berhadap-an dengan kemestian perubahan dan salah satu pendorongnya adalah bahwa pendidikan harus memberikan jawaban atas persoalan-persoalan kehidupan yang terus berubah atau berbeda dari sebelumnya. (Adang Hambali, t.th: 1).

\section{PEMBAHASAN}

\section{Definisi Sistem}

Kata sistem berasal dari Bahasa Yunani yaitu systema yang berarti "cara atau strategi". Dalam Bahasa Inggris yaitu system berarti "sistim, susunan, jaringan, cara". Sistem diartikan juga sebagai strategi, cara berpikir atau mo del berpikir. (Made Pidarta, 2002: 26). Sistem (systema) juga mengandung arti himpunan bagian atau komponen yang saling berhubungan secara teratur dan merupakan satu keseluruhan. (Tatang Saripudin, 2008: 84).

Roger A. Kanfman mendefinisikan sistem sebagai suatu totalitas yang tersusun dari ba-gian yang bekerja secara sendiri-sendiri (inde-pendent) atau bekerja bersama-sama untuk mencapai hasil atau tujuan yang diinginkan berdasarkan kebutuhan. (Ramayulis, 2011: 19).

Johnson, Kost, Rosenzweg berpendapat bahwa sistem adalah suatu kebulatan atau ke-seluruhan yang kompleks atau terorganisir; suatu himpunan atau perpaduan hal-hal atau bagian-bagian yang membentuk suatu kebulat-an atau keseluruhan yang kompleks. (Anas Sudjana, 1997: 21-26)

Berdasarkan definisi tersebut, sistem me-miliki unsur-unsur yang terdiri dari: himpunan bagian-bagian, bagian-bagian saling berhubung an, masing-masing bagian bekerja secara mandiri dan bersama-sama yang satu sama lain saling mendukung, semuanya ditujukan untuk mencapai tujuan bersama, dan terjadi pada lingkungan yang kompleks atau rumit. Pada dasarnya pengertian sistem menunjuk pada dua hal pokok yakni pada wujud (en- 
tity) atau benda tertentu, dan kepada suatu tata cara atau metode pemecahan masalah yang kemudian disebut pendekatan sistem. Pendekatan sisitem digunakan dalam rangka memahami sesuatu sebagai keseluruhan yang terpadu dan atau dalam rangka memecahkan permasalahan-permasalahan tertentu misalnya tentang pendi-dikan atau pendidikan nasional. (Anas Sudhana, 1997: 21-26

Istilah sistem baru akan memiliki pengerti-an yang jelas jika dihubungkan dengan istilah lain yang mensifatinya, seperti sistem pendidik-an, sistem politik, sistem ekonomi, dan sistem keamanan. (Supiana, 2008: 13). Dengan de-mikian, konsep sistem (system concept) meru-pakan dasar untuk munculnya pandangan sis-tem (system view) dan pendekatan sistem (sy-stem approach).

\section{Karakteristik Sistem}

Secara faktual sistem memiliki berbagai wujud dengan berbagai ciri yang sama, antara lain: a) Hierarchy, suatu sistem terdiri dari sejumlha sistem atau komponen; b) Differentiation, setiap subsistem atau kom-ponen membentuk sistem yang melakukan fungsi khusus; c) Interrelated and interdependence, setiap komponen pembentuk sistem saling berhubungan dan saling ketergantungan satu sama lain; d) Wholism, semua komponen yang memben-tuk sistem merupakan keseluruhan yang kompleks dan terorganisir; e) Goal seeking, setiap sistem memiliki tujuan karena setiap kegiatan atau perilakunya mengarah pada pencapaian tujuan; f) Transformation, untuk mencapai tujuan setiap sistem melakukan transformasi, yaitu mengubah input menjadi output; g) Feedback and correction, untuk kelangsung-an hidup dan mempertahankan prestasinya setiap sistem melakukan fungsi control yang mencakup monitoring dan koreksi berdasar-an umpan balik; h) Equifinality, pada setiap sistem terbuka keadaan akhir yang sama dapat dicapai dari berbagai macam titik tolak, hasil yang sama dpat dicapai melalui cara-cara atau aneka macam sebab yang berbeda; i) Setiap sistem berada di dalam satu lingkung-an berupa suprasistem yang terdiri atas berbagai sistem yang secara keseluruhan membangun suatu sistem besar; j) System boundaries, setiap sistem memiliki batas-batas pemisah dari lingkungannya atau sistem lainnya; dan k) Sekalipun sistem memiliki batas-batas pe-misah dari lingkungannya, namun ada sistem yang bersifat terbuka dan ada yang bersifat tertutup.

\section{Model dan Pendekatan Sistem}

Suatu sistem biasanya disajikan dalam bentuk model. Elias M. Awad mengemukakan, model adalah suatu representasi sistem nyata atau direncanakan. Sedangkan Murdick dan Ross menjelaskan bahwa model merupakan abstaksi realitas, namun karena model tidak mampu menyajikan realitas secara rinci maka model hanya menyajikan bagian-bagian tertentu yang penting saja dalam realitas. (Tatang M. Amirin, 1996: 78).

Karni Nisjar dan Winardi menjelaskan bah-wa salah satu cara menggambarkan sistem ada lah dengan menekankan unsur input, proses, dan output. (Karni Nisjar dan Winardi, 1997: 65).

Gambar 1. Model Sistem

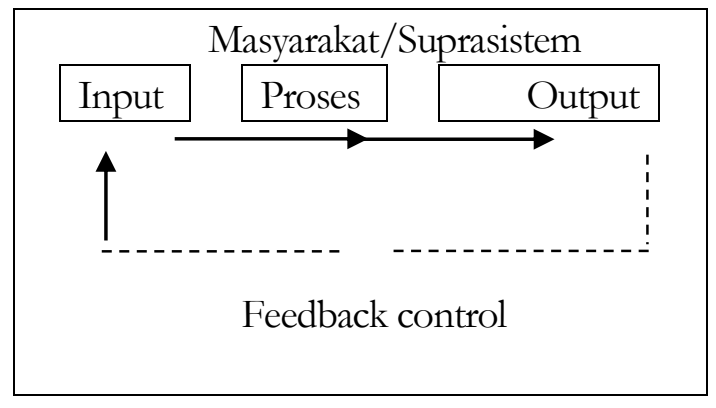

Sedangkan pendekatan sistem adalah ap-likasi pandangan sistem dalam upaya memaha-mi sesuatu atau memecahkan permasalahan. (Tatang Saripudin, 2008: 87).

Pendekatan sistem meliputi aspek filsafat sis-tem, analisis sistem dan manajemen sistem. Filsafat sistem yaitu cara berpikir mengenai fenomena secara keseluruhan 
meliputi bagian-bagian, komponen, subsistem, dan dengan titik berat pada interaksinya. Analisis sistem meru-pakan metode atau teknik dalam memecahkan masalah atau pengambilan kebijakan. Manaje-men sistem merupakan aplikasi teori dalam rang-ka mengelola sistem organisasi. Hal ini antara la-in pengenalan arus tenaga, energi, informasi, dan diperhatikan hubungan antara subsistem dengan sistem lainnya maupun antara sistem dengan suprasistemnya. (Tatang Saripudin, 2008: 87).

\section{Pendidikan Sebagai Suatu Sistem}

Pengkajian pendidikan dilihat dari pende-katan sistem, maka pendidikan merupakan sua-tu sistem, artinya sebagai suatu keseluruhan terpadu dari sejumlah komponen yang saling berinteraksi dan melaksanakan fungsi-fungsi tertentu dalam rangka membantu anak didik agar menjadi manusia terdidik sesuai dengan tujuan yang telah ditetapkan.

Ditinjau dari asal usul kejadiannya, pendi-dikan tergolong kepada sistem buatan manusia; ditinjau dari wujudnya, pendidikan tergolong kepada sistem sosial, sedangkan ditinjau dari segi hubungan dengan lingkungannya pendidik-an merupakan sistem terbuka.

Sistem pendidikan berada di dalam suatu suprasistem yaitu masyarakat. Selain sistem penddikan, di dalam suprasistem terdapat ber-bagai sistem lainnya, seperti sistem ekonomi, sistem politik, sisitem sosial, dan sistem buda-ya. Oleh karena sistem pendidikan merupakan sistem terbuka maka sistem pendidikan memi-liki ketergantungan dan saling berhubungan (in-terdepedensi dan interkoneksi) dengan ling-kungan atau sistemsistem lainnya yang ada di dalam suprasistem.

Sebagai sistem terbuka, sistem pendidikan mengambil masukan (input) dari masyarakat dan memberikan hasilnya (output) kepada masyarakat. Philip. H. Coombs mengelompok-an tiga jenis sumber input utama bagi sistem pendidikan, antara lain: 1) Ilmu pengetahuan, nilai-nilai, dan tujuan-tujuan yang berlaku di dalam masyarakat; 2) Penduduk dan tenaga kerja yang tersedia; dan 3) Faktor ekonomi. (Tatang Saripudin, 2008: 88).

Terhadap ketiga sumber utama imput sis-tem pendidikan tersebut dilakukan seleksi ber-dasarkan tujuan, kebutuhan, efisiensi, dan re-levansinya bagi pendidikan. Disamping itu, se-leksi dilakukan pula berdasarkan normanorma tertentu dengan alasan karena pendidikan ber-sifat normative. Hasil seleksi tersebut selanjut-nya dimasukan kedalam sistem pendidikan (in-put). Input sistem pendidikan dibedakan men-jadi tiga jenis, yakni: 1) Input mentah (raw input), yaitu peserta di-dik; 2) Input alat (instrumental imput), seperti kuri-kulum, pendidik, gedung, peralatan, kegiat-an belajarmengajar, dan metode; dan 3) Input lingkungan (environmental input), se-perti keadaan cuaca, keamanan masyarakat dan lain-lain. Input lingkungan ini secara langsung maupun tidak langsung dapat memengaruhi proses pendidikan. (Tatang Saripudin, 2008: 89).

Berbagai jenis input sistem pendidikan hasil seleksi akan membentuk komponenkomponen atau pelbagai subsistem pendidikan. Dalam hal ini, dilakukan diferensiasi sehingga masing-masing komponen atau subsistem memiliki fungsi-fungsi khusus. Pendidikan sebagai suatu sistem maka pelaksanaan fungsi dari masing-masing komponen tersebut secara keseluruhan diarahkan untuk mencapai tujuan pendidikan yang telah ditetapkan. Philip $\mathrm{H}$. Coombs meng-identifikasi adanya 12 komponen pokok sistem pendidikan, sebagai berikut: 1) Tujuan dan prioritas, fungsinya untuk meng-rahkan kegiatan system; 2) Anak didik, fungsinya adalah belajar hingga mencapai tujuan pendidikan; 3) Pengelolaan, fungsinya adalah merencana-kan, mengkoordinasikan, mengarahkan dan menilai system; 4) Struktur dan jadwal, fungsinya adalah mengaur waktu dan mengelompokkan anak didik berdasarkan tujuan-tujuan tertentu; 5) Isi/Kurikulum, fungsinya sebagai bahan yang harus dipelajari anak didik; 6) Pendidik, fungsinya menyediakan bahan, menciptakan kondisi belajar, dan menye-lenggarakan pendidikan; 7) Alat bantu 
belajar, fungsinya memungkin-kan proses belajar mengajar sehingga me-narik, lengkap, dan bervariasi; 8) Fasilitas, berfungsi sebagai tempat terseleng garakannya pendidikan; 9) Teknologi, berfungsi untuk mempermudah atau memperlancar pendidikan; 10) Pengawasan mutu, berfungsi membina peraturan-peraturan dan standar pendidikan (peraturan penerimaan anak didik, pembe-rian nilai ujian, dan kriteria baku); 11) Penelitian, berfungsi mengembangkan pe-ngetahuan, penampilan sistem, dan hasil kerja system; dan 12) Biaya, berfungsi sebagai petunjuk efisiensi sistem. (Tatang Saripudin, 2008: 89).

Dalam sistem pendidikan terjadi transfor-masi yaitu mengubah raw input (anak didik) agar menjadi manusia terdidik sesuai tujuan yang telah ditetapkan. Semua komponen pendidikan melaksananakan fungsinya masingmasing dan berinteraksi satu sama lain yang mengarah pada pencapaian tujuan pendidikan. Adapun output adalah manusia terdidik yang diperuntukkan bagi masyarakat atau sistemsistem lain yang berada di suprasistem. Dalam sistem pendidikan terdapat komponen pengawasan mutu (quality control) yang berfungsi melakukan proses transformasi yang menghasilkan umpan balik yang digunakan untuk melaksanakan koreksi atau perbaikan untuk proses transformasi berikutnya dan diharapkan agar sistem pendidikan mampu mengatasi entropi atau mampu mempertahankan eksistensi dan meningkatkan prestasi.
Gambar 2. Model Sistem Pendidikan

Masyarakat

Ilmu pengetahuan

Penduduk dan tenaga kerja

Ekonomi/penghasilan masyarakat

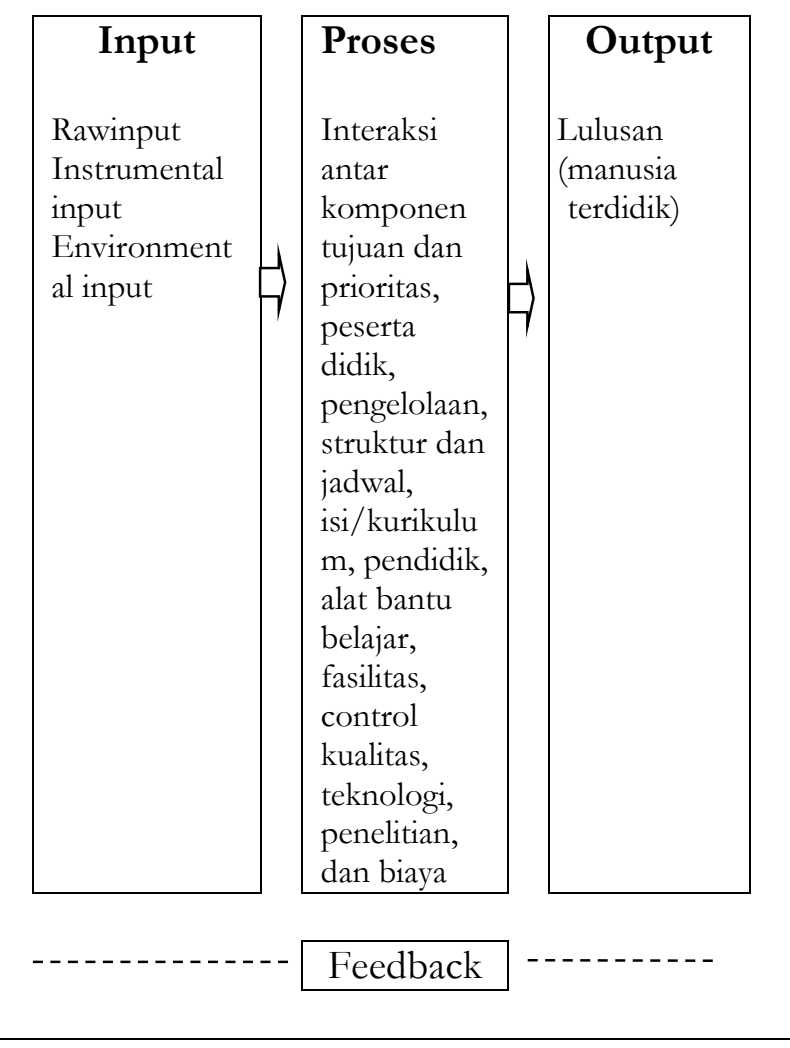

\section{Pendidikan Islam Sebagai Suatu Sistem}

Menurut Muchtar Buchori, setiap sistem pendidikan yang sehat selalu berusaha mema-hami zamannya dan berusaha memenuhi tun-tutan-tuntutannya. Setiap sistem pendidikan yang dewasa selalu berusaha mempersiapkan masyarakat yang dilayaninya mengembangkan wawasan-wawasan baru untuk mengakomodasi perubahan-perubahan yang tampak akan datang. (Hambali, t.th: 2)

Pendidikan yang terus menginteraksikan dirinya dengan dinamika masyarakatnya akan merumuskan diri dengan dinamika masyarakat nya akan merumuskan diri dalam cara yang terus-menerus baru. Maka, sistem pendidikan dituntut untuk memiliki tiga kemampuan, yaitu: 1) Kemampuan untuk 
mengetahui pola-pola perubahan dan kecenderungan yang sedang berjalan; 2) Kemampuan untuk menyusun gambaran tentang dampak yang akan ditimbulkan oleh kecenderungan-kecenderungan yang seda-ng berjalan tadi; dan 3) Kemampuan untuk menyusun program pen-yesuaian diri yang akan ditempuhnya dalam jangka waktu tertentu. (Buchori, 1994: 45).

Sebuah sistem terdiri atas beberapa sub sistem, setiap sub sistem mungkin terdiri dari beberapa sub-sub sistem, setiap sub-sub sistem mungkin terdiri dari beberapa sub-sub subsistem, begitu seterusnya sampai tidak bisa diba-gi yang disebut komponen. Komponen-komponen yang berada di dalam sistem pendidikan sangat beragam. Noeng Muhadjir mensistematisasi komponen tersebut dalam tiga kategori yakni: 1) Bertolak dari lima unsur dasar pendidikan, meliputi yang memberi, yang menerima, tujuan, cara/jalan dan konteks positif; 2) Bertolak dari empat komponen pokok pen-didikan, meliputi kurikulum, subjek didik, personifikasi pendidik dan konteks belajar-mengajar; dan 3) Bertolak dari tiga fungsi pendidikan, meliputi pendidikan kreativitas, pendidikan morali-tas, dan pendidikan produktivitas. (Noeng Muhdjir, 1978: 37).

Berdasarkan kategori sistem pendidikan ter sebut yang menjad persoalan adalah "Apakah pendidikan Islam memiliki sistem tersendiri? Ataukah sistem pendidikan Islam itu sama dengan sistem pendidikan kontemporer dengan mencantumkan beberapa ayat atau hadis yang mendukung?.” Kedua pertanyaan tersebut men jad fokus dalam menelaah pendidikan Islam sebagai suatu sistem.

Sistem pendidikan Islam adalah suatu ke-satuan komponen yang terdiri dari unsurunsur pendidikan yang bekerja sama untuk mencapai tujuan sesuai ajaran Islam. (Supiana, 2008, 15).

Pembahasan mengenai sistem pendidikan Islam harus dikaitkan dengan pemikiran filosofis pendidikan Islam.
Abdurrahman Saleh Abdullah menelaah beberapa literatur pendidikan Islam. Dari hasil studinya, ia berkesimpulan bahwa dalam pengembangan sistem pendidikan Islam itu terdapat dua corak, yaitu:

Kelompok yang menghendaki adanya keterbukaan terhadap pandangan hidup dan kehidupan non-Islami. Kelompok ini berusaha meminjam konsep-konsep non Islami dan menggabungkannya ke dalam pemikiran pendidikan Islam.

Kelompok yang berusaha mengangkat atau mengadoptasi pesan besar Ilahi keda-lam kerangka filsafat pendidikan. Isi filsafat pendidikan berasal dari Al-Quran dan Hadis. Isi tersebut masih berupa azas-azas yang mengarahkan aktivitas pendidikan. Abdurrahman Saleh Abdulah, 1982, 35-36).

Berdasarkan kedua pemikiran di atas, maka sistem pendidikan Islam memiliki dua model, yaitu model pragmatis dan model idealistik. (Muhaimin, Abdul Mujib, 1993: 6).

\section{Model Pragmatis}

Model pragmatis adalah model yang lebih mengutamakan aspek praktis dan kegunaan-nya. Artinya, formulasi sistem pendidikan Islam itu diadopsi dari sistem pendidikan kontemporer yang telah mapan. Segala sesuatu yang terda-pat pada pendidikan kontemporer dapat dikem-bangkan dalam pendidikan Islam, dengan ca-tatan transformasi pemikiran itu mendapatkan legalisasi dari nash. Jadi, nash di sini berfungsi sebagai justifikasi dan legitimasi belaka. (Ramayulis, 2011: 25).

Upaya ini sebenarnya bukanlah bermaksud mengadakan interpretasi adaptif, tetapi ber-fungsi sebagai penjabaran dan operasionalisasi universalitas Islam. Apabila pemikiran semacam itu tidak terlaksana maka akan menjadikan pola similarisasi, paralesasi, komplementasi, tetapi jika pemikiran itu terlaksana maka akan men-jadikan pola komparasi, induktifikasi, dan very-fikasi. Hanna Djumhana Bastaman, 1995: 32-33). 
Sistem pendidikan Islam yang didasarkan model ini bersumber dari pemikiran filsafat dan psikologi pendidikan kontemporer. Sistem pen-didikan yang terdapat didalam aliran progresi-visme, (Imam Barnadib, 1990: 25), esensialis-me, dan rekonstruksianisme dicarikan legalisasi dari nash. Apabila sejalan dengan azasazas nash maka sistem itu diterima, tetapi jika bertentangan maka harus ditolak. Demikian pula, pola-pola pengajaran yang berkembang pada aliran psikodinamik (klinis), psikoholistik (organismik-fenomenologis) dan psikofat dan psikobehvioristik dapat diterima bila terdapat kesesuaian dengan nash. Jika tidak sesuai maka harus ditolak. (Calvin S. Hall dan Gardner Lindzey, 1993: 8-9).

Model pragmatis ini paling banyak diminati ahli pendidikan Islam. Di samping efektivitas dan efisiensinya, model ini telah teruji keung-gulannya. Sistem pendidikan Islam yang di-kembangkan melalui metode ini memiliki posisi tersendiri bahkan mampu menjadi alternative bagi sistem pendidikan kontemporer. Diantara para ahli yang menyusun kerangka model prag-matis adalah Muhammad al-Taumiy al-Syaibaniy dalam Falsafah Pendidikan Islami-yah. Ia merumuskan persamaan dan perbe-daan ide dasar Islam dan aliran filsafat kontem-porer. Rumusan yang sama dapat diadopsi, se-mentara yang berbeda ditolak (Muhammad al-Taumiy al-Syaibaniy, 1979: 526-529).

Dengan demikian model pragmatis dilaku-kan dengan cara sebagai berikut: 1) Adopsi, yaitu mengambil secara utuh sistem pendidikan non-Islam; 2) Asimilasi, yaitu mengambil sistem pendidik-an non-Islam dengan menyesuaikannya di sana sini; dan 3) Legitimasi, yaitu mengambil sistem pendidik an non-Islam kemudian dicarikan nash un-tuk dijustifikasi. (Ramayulis, 2011: 25).

\section{Model Idealistik}

Model idealistik adalah model yang lebih mengutamakan penggalian sistem pendidikan Islam dari ajaran dasar Islam sendiri.
Ia meng-gunakan pola deduktif, dengan membangun premis mayor (sebagai postulat) yang dikaji dari nash. Bangunan primis mayor ini dijadikan sebagai "kebenaran universal dan mutlak" un-tuk diterapkan pada premis minornya. Dari pro-ses ini akhirnya mendapatkan konklusi menge-nai sisitem pendidikan Islam.

Model ini benar-benar ideal walaupun mem-butuhkan kerja ekstra. Prosedur mekanisme mode ini adalah: a) Digali pemecahan persoalan sistem pendi-dikan Islam berdasarkan nash secara lang-sung. Prosedur ini biasanya menggunakan pendekatan maudbu'iy (tematik), yaitu mengklasifikasi ayat atau hadis menurut kategorinya lalu menyimpulkannya; b) Digali dari hasil interpretasi nash para filosof muslim, seperti konsep jiwa manusia menu-rut al-Kindi, al-Farabiy, Ibnu Sina, Ibnu Maskawaih, Ibnu Thufail, Ibnu Bazzah, dan sebagainya. Konsep ini berkaitan dengan komponen peserta didik dan pendidik. Ciri utama interpretasi kelompok ini adalah sa-ngat mengutamakan pendidikan intelektual (al'aqb) 3) Digali dari hasil interpretasi para sufi muslim, seperti konsep jiwa dan ilmu al-Ghazali dan lainnya. Konsep ini berkaitan dengan komponen peserta didik, pendidik, kurikulum, metode, media dan alat pendidikan. Ciri utama interpretasi kelompok ini adalah sangat mengutamakan pendidikan intuisi (al-Qalb); 4) Digali dari hasil interpretasi para mufassir dan para ahli pendidikan modern, seperti Muhammad Abduh, Rasyid Ridha, Iqbal, dan sebagainya. Ciri utama kelompok ini adalah hasil interpretasi nash didukung oleh data ilmiah, seperti yang tertulis dalam Tafsir al-Manar. Model idealistik ini lebih didasarkan atas kerangka dasar yang diyakini kebenar-annya sehingga ia bercorak se-Islam mung-kin, namun merumuskannya memerlukan metodologi yang tepat dan benar. (Ramayulis, 2011: 25).

Kelebihan model ini adalah (1) ia dapat memproyeksikan bentuknyase-Islami mungkin, (2) ia didasarkan atas kerangka dasar yang diyakini mutlak benarnya dan mengandung nilai universal. Sedang kelemahannya dalah umat 
Islam belum memiliki metodologi yang sebaik Barat, sehingga upaya itu dikhawatirkan mengalami kegagalan, atau paling tidak mengalami keterlambatan, sementara kemajuan sistem pendidikan barat semakin malaju dan kokoh.

Untuk menghindari fanatisme dan kelemahan suatu mode, maka pendekatan yang ter baik adalah pendekatan elektik. Maksud pendekatan ini adalah mengambil suatu model yang dianggap terbaik untuk memecahkan dan mengkaji suatu persoalan, dan mengambil model lain untuk mengkaji persoalan lain jika pengambilan itu dirasa terbaik. Dengan kata lain, perumusan sistem pendidikan Islam dapat menggunakan kedua model tersebut. Kelebihannya diadopsi sedang kelemahannya dibuang.

Gambar 3. Model Dasar Sistem Pendidikan Islam

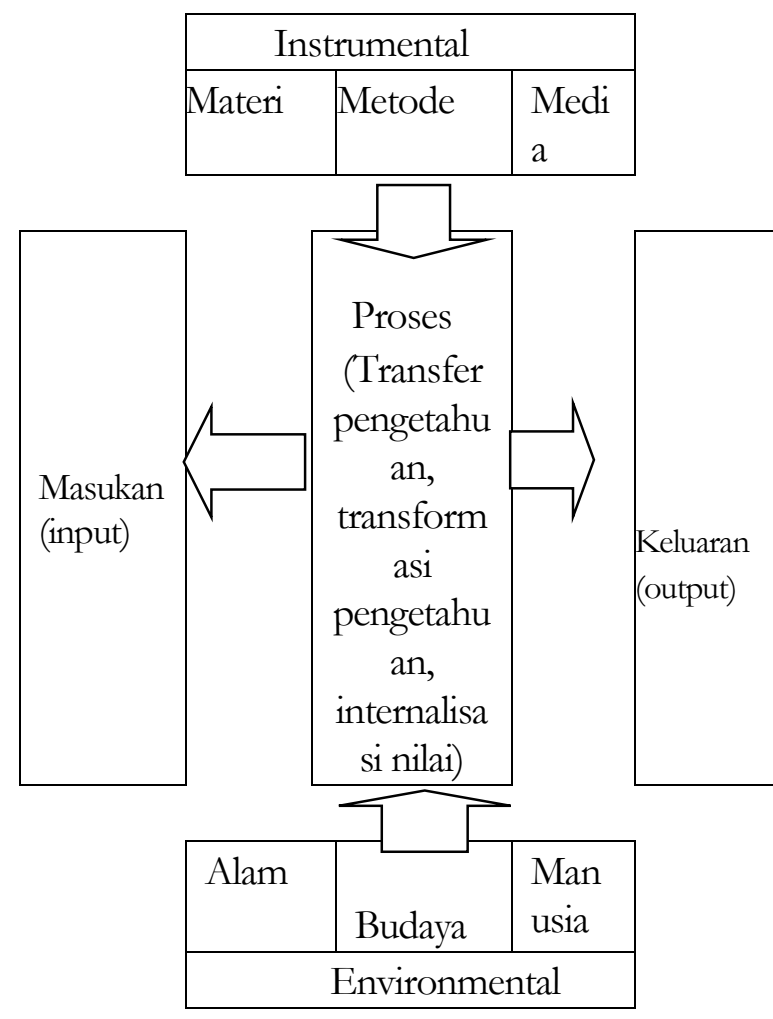

Gambar tersebut menunjukkan bahwa masukan berupa individu yang mempunyai berbagai potensi dasar yang perlu dikembangkan kemudian diproses dalam bentuk transfer pengeta huan, transformasi pengetahuan, dan internali- sasi nilai untuk menghasilkan keluaran berupa pribadi yang selalu engabdi kepada Allah dan menjadi khalifatullah $f i$ al-ard, proses ini akan terlaksana dengan baik dan sempurna bila dibantu oleh instrument berupa materi ajar, metode, dan media yang tepat dan lengkap serta environmental berupa alam, manusia, dan budaya yang kondusif, sebagai pelaku utama proses pendidikan ini adalah pendidik berupa orang tua, guru, dan tokoh masyarakat sebagai pemegang amanah dari Allah untuk melaksanakan tugas suci (pendidikan Islam).

\section{KESIMPULAN}

Pengertian sistem menunjuk pada dua hal pokok yaitu kepada suatu wujud (entity) atau benda tertentu, dan kepada suatu tata cara atau metode pemecahan masalah yang kemudian disebut pendekatan sistem. Pendekatan sistem digunakan dalam rangka memahami sesuatu sebagai keseluruhan yang terpadu dan atau dalam rangka memecahkan permasalahanpermasalahan tertentu misalnya tentang pendidikan atau pendidikan nasional.

Istilah sistem baru akan memiliki pengerti-an yang jelas dengan istilah lain yang mensifati nya, seprti sistem pendidikan, sistem politik, sistem ekonomi, dan sistem keamanan. Dengan demikian, konsep sistem (system concept) merupakan dasar untuk munculnya pandangan sistem (system view) dan pendekatan sistem (system approach).

Pendidikan merupakan suatu sistem, arti-nya sebagai suatu keseluruhan terpadu dari sejumlah komponen yang saling berinteraksi dan melaksanakan fungsi-fungsi tertentu dalam rangka membantu anak didik agar menjadi manusia terdidik sesuai dengan tujuan yang telah ditetapkan.

Pengembangan sistem pendidikan Islam itu terdapat dua corak, yaitu: pertama, Kelompok yang menghendaki adanya keterbukaan terha-dap pandangan hidup dan kehidupan non-Isla-mi. Kelompok ini berusaha meminjam konsep-konsep non Islami dan menggabungkannya ke dalam pemikiran pendidikan Islam, dan kedua, kelompok yang 
berusaha mengangkat atau mengadopsi pesan besar Ilabi ke dalam kerang-ka filsafat pendidikan. Isi filsafat pendidikan berasal dari Al-Quran dan Hadis. Isi tersebut masih berupa azas-azas yang mengarahkan aktivitas pendidikan. Maka model yang yang di-gunakan adalah model idealistik dan model pragmatis.

\section{DAFTAR PUSTAKA}

Abdulah, Abdurrahman Saleh. (1982). Educational Theory; a Quranic Outlook, Mekkah: Umm al-Qura University.

Barnadib, Imam. (1990). Filsafat Pendidikan, Sistem dan Metode, Yogyakarta: Andi Offset.

Buchori, Mochtar. (1994). Pendidikan dalam Pembangunan, Yogyakarta: PT Tiara Wacana Yogya.

Calvin S. Hall dan Gardner Lindzey. (1993).

Teori-Teori Psikodinamik (Klinis), Yogyakarta: Kanisius

Djumhana Bastaman, Hanna. (1995). Integrasi Psikologi dengan Islam, Yogyakarta: Pustaka Pelajar.

Hambali, Adang. (TT). Pendidikan Kesalehan Transformatif Gagasan Pengembangan Epistimologi dalam Pendidikan Islam, Bandung: CV. Insan Mandiri.

Karni Nisjar dan Winardi. (1997). Teori Sistem daan Pendekatan Sistem dalam
Bidang Manajemen, Bandung: Mandar Maju.

M. Amirin, Tatang. (1996). Pokok-pokok Teori Sistem, (Jakarta: PT Rajawali Pers.

Muhaimin, Abdul Mujib. (1993) Pemikiran Pendidikan Islam, Kajian Filosofik dan Kerangka Dasar Operasionalisasinya, Bandung: Trigenda Karya.

Muhammad al-Taumiy al-Syaibaniy. (1979). Falsafah Pendidikan Islam, Jakarta: Bulan Bintang. 1979).

Muhdjir, Noeng. (1892). Ilmu Pendidikan dan Perubahan Sosial; Suatu Teori Pendidikan, Yogyakarta: Rake.

Pidarta, Made. (2002). Landasan Kependidikan Stimulus Ilmu Pendidikan Bercorak. Indonesia, Jakarta: Kalam Mulia.

Ramayulis. (2011). Ilmu Pendidikan Islam, Jakarta: Kalam Mulia.

Sudjana, Anas. (1997). Pengantar Administrasi Pendidikan Sebagai Suatu Sistem, Bandung: Rosda Karya.

Supiana. (2008). Sistem Pendidikan Madrasah Unggulan, (Jakarta: Badan Litbang dan Diklat Departemen Agama RI.

Tatang Saripudin, Tatang. (2008). Pengantar Pendidikan, Jakarta: Universitas Terbuka. 